\title{
Experimental Identification of Linear Actuator Properties
}

\author{
Michal Kelemen *, Ivan Virgala, Lubica Miková and Peter Frankovský \\ Technical University of Košice, Faculty of Mechanical Engineering, Letná 9, 04200 Košice
}

\begin{abstract}
Michal Kelemen, doc. Ing. PhD., He received M.S. degree in mechanical engineering from Technical University of Košice, Slovakia in 1998 and Ph.D. degree in Mechatronics from Technical University of Košice, Slovakia in 2002. He is an associated professor of the Department of Mechatronics at the Faculty of Mechanical Engineering at the Technical University of Košice, Slovakia. He has been awarded the 1998 "Price of the VolksBank" for the best M.S. graduate and 2007 Price "Scientist of the year." His research interests include mechatronic systems, intelligent robotic systems, dust mass concentration measurement, measurement of non-electric quantities, and microcomputer systems. He has authored more than 200 journal and conference papers on these topics.
\end{abstract}

Ivan Virgala, Ing. PhD., He received M.Sc. degree in Mechatronics from Technical University of Košice, Slovakia in 2009 and PhD. degree in Mechatronics from Technical University of Košice, Slovakia in 2012. He is a researcher in Department of Mechatronics at Faculty of Mechanical Engineering at Technical University of Košice, Slovakia. He has been awarded by "medal of dean" for excellent study. He is an editorial board member of 3 foreign scientific journals. His research field is design, modeling and control of manipulators, mobile robots, snake robots, humanoid robots and embedded systems. He has authored more than 60 journal and conference papers on these topics. Lubica Miková, Ing. PhD., She received M.S. degree in mechatronics from Technical University of Košice in 2007 and PhD. degree in Mechatronics from Technical University of Košice, Slovakia in 2011. She is a researcher of the Department of Mechatronics at the Faculty of Mechanical Engineering at the Technical University of Košice, Slovakia. Her research interests include mechatronics systems and robotics. She has authored more than 60 journal and conference papers on these topics.

Peter Frankovský, doc. Ing. PhD., He received M.Sc. degree in Applied Mechanics from Technical University of Kosice, Slovakia in 2006 and PhD. degree in Applied Mechanics from Technical University of Kosice, Slovakia in 2010. He is an associated professor of the Department of Mechatronics at Faculty of Mechanical Engineering at Technical University of Kosice, Slovakia. He has authored more than 100 journal and conference papers on these topics.

Abstract: Paper deal with experimental identification of the electro-mechanical linear actuator properties. Force-velocity dependence and positional accuracy has been identified. Results show the difference between the data declared via producer and experimental obtained data.

Keywords: Actuator, position, velocity, measurement.

\section{Introduction}

The aim of the paper is to identify properties of the linear electro-mechanical actuators. Linear actuator converts the electrical energy to mechanical work as force effort with rectilinear stroke. The actuator is suitable for applications where linear movements generating are needed. Small linear actuators are a superior alternative to designing with awkward gears, motors, servos and linkages $[1,2,3]$. 
The linear actuator PLX is designed to move push or pull loads along its full stroke length. The speed of travel is determined by the gearing of the actuator and the load or force the actuator is working against at a given point in time. When the actuator moves to a position within $0.5 \mathrm{~mm}$ of its fully-retracted or fully-extended stroke endpoint, a limit switch will stop power to the motor. When this occurs, the actuator can only be reversed away from the stroke endpoint. Once the actuator is positioned away from its stroke endpoint, normal operation resumes. Tested actuators have been with RC Servo Interface Mode. This is a standard hobby-type remote-control digital servo interface (CMOS logic), compatible with servos and receivers from various manufacturers. The desired actuator position is input to the actuator on lead 4 as a positive 5 Volt pulse width signal. A $1.0 \mathrm{~ms}$ pulse commands the controller to fully retract the actuator, and a $2.0 \mathrm{~ms}$ pulse signals full extension.

The linear actuators PQY are complete, self contained linear motion devices with position feedback for sophisticated position control capabilities (our tested model), or end of stroke limit switches for simple two position automation. Driving of it is possible with simple applying of DC voltage to extend the actuator, and reverse the polarity to retract it. This can be accomplished manually with a DPDT switch or relay, or using an $\mathrm{H}$-Bridge circuit. When power is removed the actuator will also hold its position, unless the applied load exceeds the backdrive force. The actuators have limit switches that will turn off power to the motor when the actuator reaches within $1 \mathrm{~mm}$ of the end of stroke.

Drive unit of both actuators is based on miniature DC motor with gears. Rotation output is transformed to linear motion through the using of a screw mechanism. Overloading the actuator under power for short periods of time (several seconds) will not damage the actuator.

\section{Specifications of Actuators}

\section{A. PLX actuator}

Maximum stroke is defined at the $100 \mathrm{~mm}$ with positional accuracy $0,3 \mathrm{~mm}$. Peak Power Point is $12 \mathrm{~N}$ at velocity $11 \mathrm{~mm} / \mathrm{s}$. Peak Power Point is defined as maximum power and the speed it can move at that force. Peak Efficiency Point is $6 \mathrm{~N}$ at velocity $16 \mathrm{~mm} / \mathrm{s}$. Peak Efficiency Point is defined as the speed and force at which the device is the most efficient. Maximum speed without load is $23 \mathrm{~mm} / \mathrm{s}$. A powered-off actuator will statically hold a force up to the Backdrive Force $43 \mathrm{~N}$. Gearing is at the value 50. Overall weight is $65 \mathrm{~g}$. Load curve is shown on fig 1 .

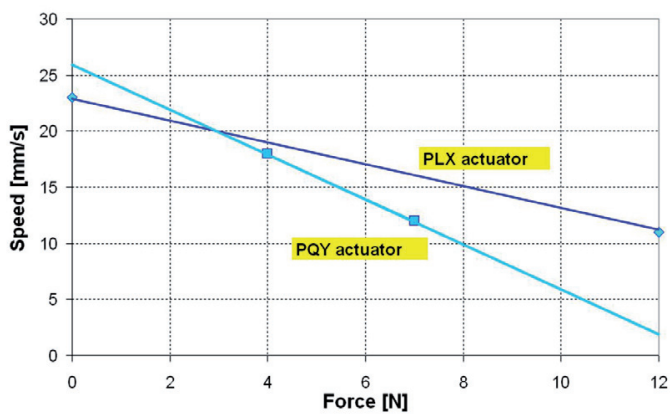

Fig. 1: Load characteristic of the actuators PLX and PQY defined by producer.

\section{B. PQY actuator}

Maximum stroke is defined at the $20 \mathrm{~mm}$ with positional accuracy $0,1 \mathrm{~mm}$. Peak Power Point is defined as $7 \mathrm{~N}$ at velocity $12 \mathrm{~mm} / \mathrm{s}$ and Peak Efficiency Point is $4 \mathrm{~N}$ at velocity $18 \mathrm{~mm} / \mathrm{s}$. Maximum speed without load is $25 \mathrm{~mm} / \mathrm{s}$. A powered-off actuator will statically hold a force up to the Backdrive Force 15 N. Maximum force (lifted) is $9 \mathrm{~N}$. Gearing is at the value 30. Overall weight is $15 \mathrm{~g}$. Load curve is shown on fig. 1.

The actuators have no built in controller, but do provide an analog position feedback signal that can be input to an external controller.

\section{Measurement experimental stand}

All experimental works has been done at the measurement stand (fig. 2, 3). One end of the actuator is fixed to the frame and free end is connected with slide which is able to move on guiding rod. Slide is connected with hook for placing of the load weight. Position of the slide is sensed with resistive sensor. Measured position is acquired through the input/output card MF624 on PC. Measurement has been managed through the Real Time Toolbox under the Matlab/Simulink. Measurement has been repeated with various weights.

Output from the position sensor has been measured with card as the voltage. Assignment of the length to the measured voltage is possible to 
do through the calibration process. Calibration has to be realized with parallel length etalons (fig. 4).

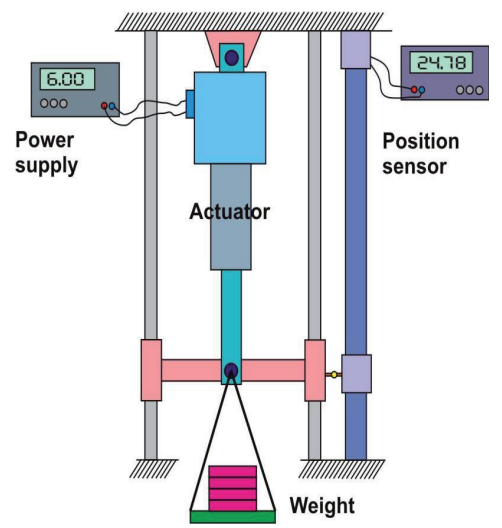

Fig. 2: Scheme of measurement stand for the testing of the actuators.

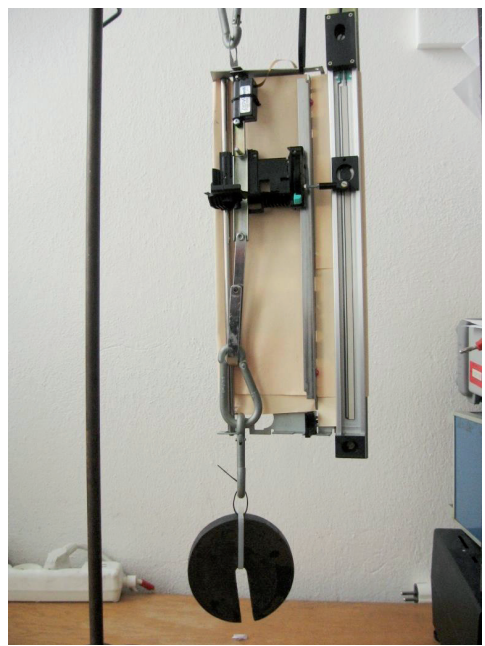

Fig. 3: Measurement stand for the testing of the actuators

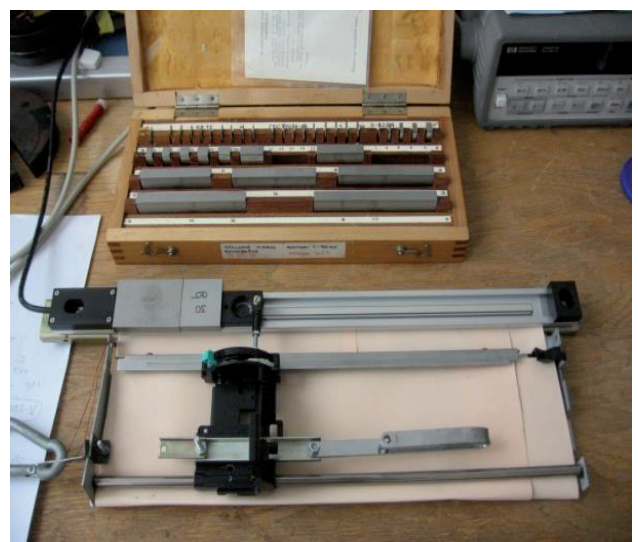

Fig. 2: Calibration of the stroke measurement.
Calibration process (fig. 4) has been made at the every 5 th millimeter and obtained calibration curve has been included into Matlab environment for recalculating of measured voltage from position sensor.

\section{Actuator load curves}

Load curves have been identified through the measurement of the stroke velocity at the various forces (load weights). First measurement has been realized without additional load. Load weight has been increased at the every next measurement until the full actuator stroke occurs. Results (fig. 5) of the PLX testing shows the maximum lift force $28 \mathrm{~N}$. Peak Power Point is $28 \mathrm{~N}$ at velocity $7,6 \mathrm{~mm} / \mathrm{s}$. Results (fig. 6) of the PQY testing shows the maximum lift force $17 \mathrm{~N}$. Peak Power Point is $17 \mathrm{~N}$ at velocity $16,5 \mathrm{~mm} / \mathrm{s}$.

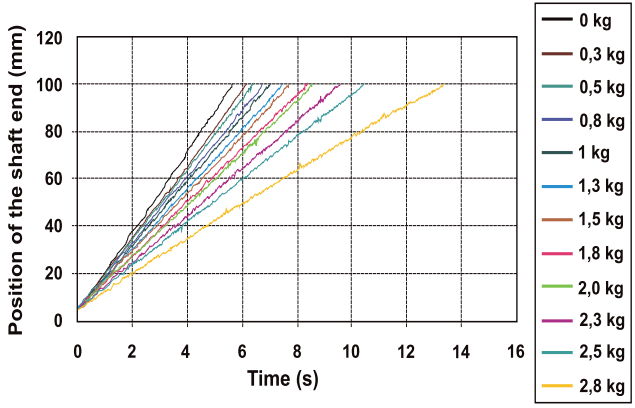

Fig. 5: Time dependence of the actuator PLX stroke at various weights. (Expanded uncertainty for position measurment was 0,05 $\mathrm{mm}$, and for time was 0,001s).

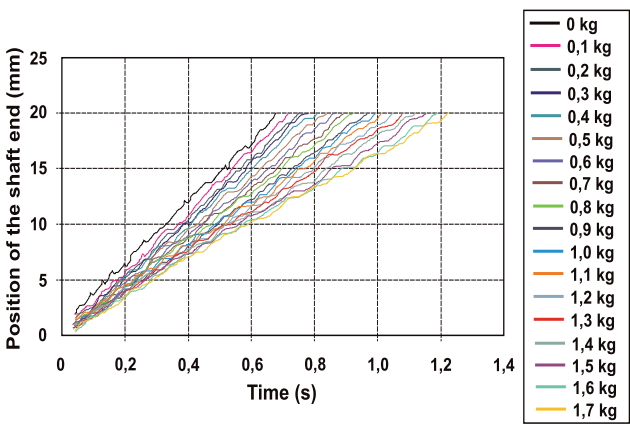

Fig. 6: Time dependence of the actuator PQY stroke at various weights. (Expanded uncertainty for position measurment was 0,05 $\mathrm{mm}$, and for time was 0,001s).

Results of time stroke measurement of the actuators can be drawn into load curves (fig. 7, fig. 8). Experimental measurements shows that actuator PLX has maximum lift force only $28 \mathrm{~N}$ unlike the 
datasheet value $(45 \mathrm{~N})$ but maximum speed without load $(17,4 \mathrm{~mm} / \mathrm{s})$ is much higher than datasheet value $(5 \mathrm{~mm} / \mathrm{s})$.

Actuator PQY has been better than datasheet facts. Maximum speed without load is $30 \mathrm{~mm} / \mathrm{s}$ unlike the datasheet value $(25 \mathrm{~mm} / \mathrm{s})$. Maximum force (lifted) is $17 \mathrm{~N}$, what is much more than datasheet value $(9 \mathrm{~N})$.

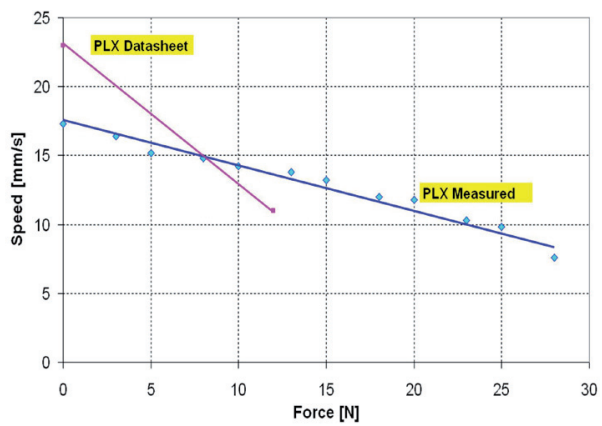

Fig. 7: Load curve of PLX Actuator (Expanded uncertainty for speed measurement was $0,1 \mathrm{~mm} / \mathrm{s}$, and for measurement of force was $0,1 N)$.

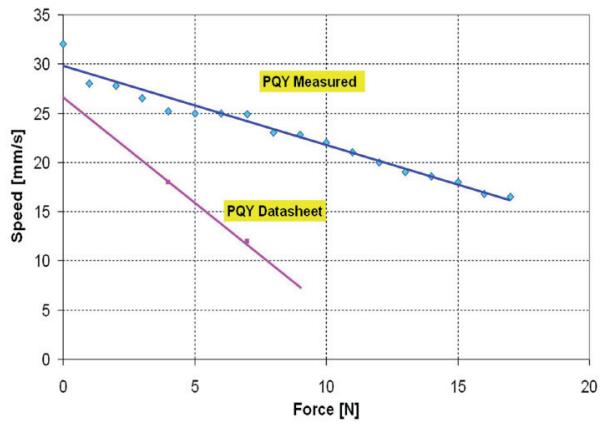

Fig. 8: Load curve of PQY Actuator (Expanded uncertainty for speed measurement was $0,1 \mathrm{~mm} / \mathrm{s}$, and for measurement of force was $0,1 N$ ).

Actuator PLX has been also tested for position accuracy. The testing has been made at the five selected position. Every tested position has been positioned and measured ten times. Span of the deviations from the average of measurements is shown on figure 9. Only one position value overcomes nominal defined position accuracy. This overrun could be caused via uncertainty of measurement (Expanded uncertainty was 0,05 mm) or any unknown random errors.

The linear actuator has been used for rectilinear movement in snake like robot (fig. 10). The key benefit is small dimension and also compact design, which enables using without any other additional

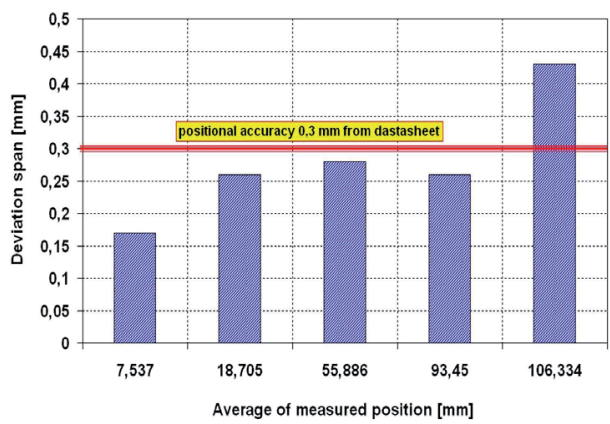

Fig. 9: Deviation span from accuracy testing of PLX actuator (EXpanded uncertainty for position measurement was 0,05 $\mathrm{mm}$ ).

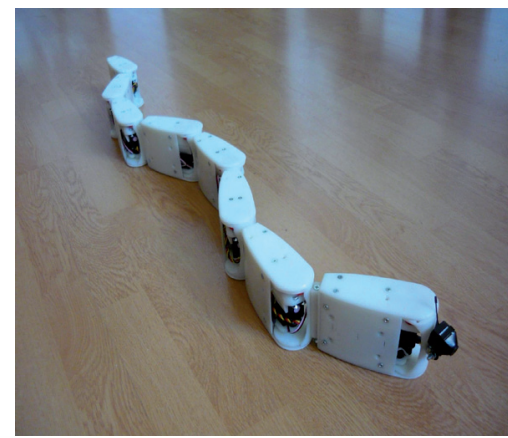

Fig. 10: Snake like robot using the linear actuator.

accessories. The actuator can be simple controlled directly via using of microcontroller.

\section{Conclusions}

The linear actuator PLX and PQY are compact actuator for mechatronic application with simple using. The main advantage of these type actuators is that they directly contain transformation mechanisms from rotation to translation motion [4 8]. Design of the mechatronic application needs the exactly defined load characteristic and positional accuracy. Experiments show that properties of these actuators differ from properties mentioned in datasheet. It is important to note that only one piece of both type of actuators have been tested. Variation from datasheet can be caused by different condition of measurement or different way of loading etc. Consequently, for overall evaluation it is necessary to test more pieces of them in specific condition in accordance with desired application.

\section{Acknowledgments}

The authors would like to thank to Slovak Grant Agency - project KEGA 048TUKE-4/2014 
and VEGA 1/1205/12. Paper is the result of the Project implementation: University Science Park TECHNICOM for Innovation Applications Supported by Knowledge Technology, ITMS: 26220220182, supported by the Research \& Development Operational Programme funded by the ERDF.

\section{References}

[1] Laurean, B., Emanoil, T.: New solution for telescopic robotic arm. Applied Mechanics and Materials. Volume 658, 2014, Pages 557-56

[2] Salloum, R., Moaveni, B., Arvan, M.R.: Robust PID controller design for a real electromechanical actuator. Acta Polytechnica Hungarica. Volume 11, Issue 5, 2014, Pages 125-144

[3] Salloum, R., Arvan, M.R., Moaveni, B.: Identification, uncertainty modelling, and robust controller design for an electromechanical actuator.

[4] CARE 2013 - 2013 IEEE International Conference on Control, Automation, Robotics and Embedded Systems, Proceedings. 2013, Article number 6733690

[5] Juhász, L., Maas, J.: Control of hybrid nanopositioning systems for trajectory-tracking applications. Mechatronics. Volume 23, Issue 6, September 2013, Pages 617-629

[6] Zhang, W.-M., Yan, H., Peng, Z.-K., Meng, G.: Electrostatic pull-in instability in MEMS/NEMS: A review. Sensors and ACtuators, A: Physical. Volume 214, 1 August 2014, Pages 187218

[7] Trebuňa, F., Šimčák, F., Huňady, R.: Operational vibration analysis of railway transport complex. Acta Mechanica Slovaca. Roč. 16, č. 3 (2012), s. 26-32. - ISSN 1335-2393.

[8] Trebuňa, F. et al.: Methodology for experimental verification of safety of packages for transport of spent nuclear fuel. Acta Mechanica Slovaca. Roč. 16, č. 3 (2012), s. 34-41. - ISSN 1335-2393. 
Acta Mechanica Slovaca

Journal published by Faculty of Mechanical Engineering - Technical University of Košice 